\title{
O Problema da Experimentação na Inovação Tecnológica*
}

\author{
Thales Novaes de Andrade \\ Professor do Departamento de Ciências Sociais da \\ Universidade Federal de São Carlos - UFSCar
}

\section{RESUMO}

A problemática da inovação tecnológica está despertando grande interesse da parte dos cientistas sociais. Nas últimas décadas diversos trabalhos foram desenvolvidos enfocando a construção de ambientes de inovação e capital social. Percebe-se que os estudos sobre sistemas e ambientes de inovação estão tirando importância da discussão propriamente tecnológica sobre as práticas de inovação, na medida em que focam preferencialmente a gestão e organização de fluxos de conhecimento e formação de redes. O presente trabalho pretende discutir a relação entre gestão tecnológica e prática dos inovadores, tendo por base o trabalho de filósofos e sociólogos das técnicas.

\footnotetext{
* Gostaria de expressar meus sinceros agradecimentos aos pareceristas anônimos da Revista que com suas sugestões me ajudaram a aprimorar o texto.
} 
PalaVRas-ChaVE | Experimentação; Inovação; Tecnologia; Conhecimento

Códigos JEL | O32; O33

\begin{abstract}
The problem of technological innovation demands increasing concern among social scientists. In the last decades many researches were conducted focusing on innovation environments and social capital. It seems clear that researches focusing on a properly technological dimension on innovation practices are becoming less relevant in comparison with innovation systems and environments, which deal specially with flows management and networks. The present study deals with the relationship between technological management and innovators practices, based on the philosophy and sociology of technology.
\end{abstract}

KEYWORDS | Experiment; Innovation; Technology; Knowledge

JEL-CODES | O32; O33 


\section{Introdução}

Implementar uma política tecnológica e de inovação implica levar em conta diversas variáveis econômicas, como tendências de mercado e a oferta de insumos. A qualificação de mão-de-obra emerge como variável dependente dentro de uma contabilidade precisa, em que o surgimento de novos componentes e o cruzamento entre setores industriais precisam se submeter a um conjunto de previsões e acordos institucionais (patentes, lançamento de editais, licitações, etc.) (Albagli \& Maciel, 2004).

A inovação reveste-se de um caráter gerencial e administrativo sofisticado, e os gestores e policy-makers precisam atuar continuamente para dar coerência e integração às diferentes áreas de pesquisa, desenvolvimento e difusão tecnológica. Vive-se em um mundo em que o desenvolvimento tecnológico avança ao passo de sua burocratização. Todo um aparato jurídico e organizacional é criado em torno das práticas de inovação tecnológica, em que os gestores e investidores dividem espaço com os inventores e técnicos (Trigueiro, 2002).

Faz-se imperativo transformar conhecimento científico em riqueza, e com isso aumentar a competitividade no cenário internacional. Nessa conjuntura, o desenvolvimento técnico parece estar claramente traçado: ele deve submeter-se às novas modalidades de gestão e aos imperativos do processo produtivo, respeitando estritamente os planejamentos estratégicos e os indicadores econômicos de desempenho. Segundo Zackiewicz, esse controle externo da ciência e tecnologia remonta a algumas décadas, implicando perda de autonomia e autoprogramação.

"As práticas da escola de forecasting foram incentivadas pelos esforços dos governos em legislar sobre a ciência - especialmente sobre a custosa big science - e produzir accountability. Embora ainda sob perspectivas bastante diferentes, a partir do pós-guerra tanto a avaliação (externa) das atividades cientificas quanto a previsão de seus avanços passaram a ser cada vez mais tratados por métodos com fortes influências da teoria econômica. A ciência, cada vez mais, precisava provar quantitativamente sua utilidade. (Zackiewicz, 2003:196-7) 
Estudos de viabilidade funcional servem para prever e ajustar as técnicas à realidade empresarial. Esses aspectos indicam a necessidade de se estudar as condições e práticas concretas e contextualizadas de inovação tecnológica, e a Sociologia da Inovação possui ferramentas analíticas propícias a essa discussão. Determinadas correntes da área de inovação partem do princípio de que a constituição da Sociedade do Conhecimento solicita um enquadramento gerencial qualificado para a disseminação de informaçôes e práticas de compartilhamento de novas tecnologias (Cassiolato \& Lastres, 2000; Dodgson, 2005).

Dentro do estabelecimento de uma agenda de inovação, quais são os procedimentos dominantes: aqueles voltados ao aprimoramento das práticas de gestão e alcance de metas; ou aqueles voltados à contínua experimentação técnica, com menor interferência administrativa e financeira? O interesse do presente artigo é discutir os efeitos da gestão tecnológica sobre a criação técnica, e a importância dessa última para o aperfeiçoamento da inovação. Mais especificamente, a meta do trabalho consiste em propor uma revisão da relação entre gestão tecnológica e gesto técnico dentro de novas trajetórias e formas de conceber a inovação tecnológica. Ao final, o artigo pretende mostrar que diferentes áreas como economia da inovação, sociologia das técnicas e filosofia da tecnologia podem colaborar mutuamente no refinamento dessa discussão.

Em um primeiro momento será discutido o papel da experimentação dentro da inovação industrial e o impasse vivenciado atualmente do desenvolvimento de aptidões tecnológicas. Depois enfocaremos como a perspectiva da sociedade do conhecimento traz em seu bojo a questão do gerenciamento da inovação na economia moderna e seus problemas. Posteriormente o interesse recairá sobre as possibilidades abertas pela experimentação técnica e seus efeitos no desenvolvimento tecnológico, procurando aproximar questões econômicas e sociológicas no tocante à problemática da gestão da inovação.

Ao final espera-se lançar bases para uma discussão renovada sobre a relação entre o gesto técnico e o gerenciamento da criação técnica na esfera inovativa, e mostrar as possíveis aproximações entre áreas tradicionalmente distintas, a filosofia das técnicas e a economia da inovação. 


\section{Experimentação na inovação industrial}

Desde as formulações de J. Schumpeter no início do século XX, a problemática da inovação esteve claramente articulada com a teoria da empresa (Schumpeter, 1982). O empresário moderno representa a síntese entre a iniciativa organizacional e a pujança de novos conhecimentos e ferramentas técnicas. Apesar do empresário empreendedor não ser diretamente um agente controlador da experimentação técnica e inferência indutiva, ele viabiliza a recorrência entre essas práticas e o universo produtivo.

No pensamento neo-schumpeteriano, o desenvolvimento empresarial se articula à internalização de práticas de pesquisa e desenvolvimento e à cotidianização da renovação de processos na atividade econômica.

Porém, até o século XIX, a responsabilidade pelo avanço industrial nas empresas era devido mais à atuação de operários e inventores do que aos parâmetros da lógica produtiva. Segundo Freeman, nos primeiros séculos da industrialização dos países avançados,

"o progresso técnico foi rápido, mas as técnicas eram tais que a experiência e o engenho mecânico motivaram muitas melhorias como resultado da experiência direta e da experimentação em escala reduzida. A maioria das patentes daquele periodo se deve a "mecânicos" ou "maquinistas" que realizavam seu próprio trabalho de "desenvolvimento" paralelamente à produção ou de forma privada. (Freeman, 1975:28-9)

Segundo o mesmo autor, é possível perceber que em alguns ramos específicos, as empresas podem dispor de departamentos técnicos ou de engenharia que contribuem muito para o aperfeiçoamento tecnológico, por meio de princípios de experimentação e conhecimento tácito.

$\mathrm{Na}$ construção do chamado capitalismo informacional, Castells (1999) aponta que a inventividade dos pioneiros e líderes de empreendimentos tecnológicos foi um fator de vital importância para a cristalização de um conjunto de instituições e redes de empresas. Não apenas as rotinas administrativas fundaram os pilares do capitalismo informacional moderno, mas a experimentação constante e aberta fez com que áreas de conhecimento 
diferentes pudessem convergir nesse idioma, estabelecendo um diálogo constante de técnicos e empresários.

Mas na medida em que o setor de Pesquisa e Desenvolvimento (P\&D) passa a compor a estrutura interna das empresas, todo um conjunto de práticas se modifica. Técnicos e cientistas passam a articular suas atividades com princípios organizacionais mais precisos e controlados, não mais respeitando incondicionalmente seus hábitos e rituais.

$\mathrm{Na}$ maior parte do tempo técnicos e engenheiros precisam se dedicar a resolver problemas relacionados ao ritmo e ao processo normal da produção, deixando para segundo plano ou de forma controlada e subsidiária a prática de experimentação e testes. Os experimentos tendem a ficar confinados a atividades e protótipos fora da cadeia de produção, enquanto que essa passa a demandar cada vez mais a presença de técnicos e engenheiros (Freeman, 1975:34-5).

Faz-se necessário entender o acoplamento instaurado entre os diferentes domínios da empresa e a atitude de cientistas e tecnólogos. Segundo Dosi (1988), a competitividade da empresa resulta de uma aproximação entre a produção e o processo inovativo, em que as corporações secretam as habilidades e memórias indispensáveis para adaptarem-se aos constrangimentos ambientais. Os técnicos e engenheiros, portanto, não são os agentes preferenciais para a resolução de problemas situados na interface entre a empresa e o mercado, essa conjugação complexa exige das firmas a capacidade de previsão e busca de oportunidades contextuais para um bom desempenho econômico.

Essa discussão reaparece claramente nas avaliações sobre o desempenho das economias asiáticas. Segundo Dodgson (2005), nos países asiáticos de industrialização recente, é possível perceber como o comportamento das empresas frente à experimentação técnica influencia os processos de inovação tecnológica. Determinadas empresas podem ter um bom desempenho inovativo em termos de aquisição de patentes, mas a falta de criatividade tecnológica impede o alcance de metas mais ambiciosas. As condições de trabalho do sistema de $\mathrm{P} \& \mathrm{D}$ muitas vezes inviabilizam a construção de práticas inovativas consistentes e duradouras, e a liderança tecnológica se compromete. Ele cita o caso da Samsung como emblemático dessa tensão. 
"Atualmente, a Samsung emprega 14.500 pesquisadores, possui mais de 20 laboratórios de pesquisa, registra acima de 750 patentes por ano nos Estados Unidos e tem atraido parcerias de cooperação em P\&D com muitas das melhores empresas de alta tecnologia do mundo. No entanto, continua sendo frágil a capacidade de muitas empresas do Leste Asiático, como a Samsung, de lidar com a criatividade tecnológica, assim como com a concorrência internacional, especialmente em relação à superburocratização (e, portanto, às restriçôes à criatividade) da atividade de P\&D.” (Dodgson, 2005:332)

As empresas altamente competitivas enfrentam o dilema de investir em políticas avançadas de inovação que não representam, contudo, incremento em termos de criatividade e investimento propriamente tecnológico. Experimentação tecnológica e inovação não são atividades diretamente relacionadas, de modo que é possível para determinados ramos industriais adquirir grande número de patentes sem ampliar desempenho tecnológico próprio.

Esse é um aspecto de grande importância na discussão sobre o papel da experimentação técnica na lógica empresarial de inovação. O desenvolvimento de aptidões tecnológicas é considerado um aspecto-chave na dinâmica inovativa de países de industrialização recente, mas dentro de um contexto de elevados padrões de inovação através de investimentos estrangeiros, pode ocorrer uma tendência inversa. Ainda segundo Dodgson,

“...quando se incorpora tecnologia na nova capacidade de produção por meio de projetos turn-key e de investimento direto estrangeiro, limita-se a profundidade das aptidóes tecnológicas acumuladas nos paises em industrialização... embora a adoção de políticas de estímulo ao investimento de empresas estrangeiras possa ter melhorado os recursos empresas parceiras locais e algumas limitadas aptidóes de difusão de tecnologia, as empresas locais não chegaram a desenvolver aptidôes de criação de tecnologia”. (Dodgson, 2005:338)

Em determinados contextos produtivos, as aptidões tecnológicas são subordinadas a mecanismos de fornecimento de componentes e difusão de conhecimentos específicos. A experimentação técnica e a prática indutiva dos engenheiros e outros profissionais diretamente ligados à prática tecnológica não repercutem fortemente nos contornos da inovação industrial. Esse di- 
agnóstico aponta para uma tendência de recrudescimento das rotinas administrativas das empresas, muitas vezes impermeáveis às demandas da própria capacidade tecnológica instalada.

Ao analisar a constituição de redes de atores ligados à pesquisa de biotecnologia no Brasil, Trigueiro (2002) avalia que técnicos e empreendedores submetem suas agendas de trabalho a aspectos ligados a gestão de projetos e aperfeiçoamento organizacional. Aparece claramente um conflito entre a aptidão tecnológica dos pesquisadores e técnicos e a capacidade de gestão e obrigações corporativas.

Essa temática das aptidóes coloca em relevo um aspecto que precisa ser levado em conta na discussão atual sobre inovação e indústria: a relação entre a prática gerencial e o fomento à criatividade e ao gesto técnico. Nesse debate, a perspectiva da sociedade do conhecimento e outras formas de geração de informação são cruciais.

\section{Sociedade do conhecimento e inovação tecnológica}

A discussão sobre tecnocracia e burocratização da ciência marcou o pensamento sociológico nos anos 1960 e 1970, chamando atenção para o caráter gerencial e formalizado do mundo técnico no capitalismo avançado (Habermas, 1983; Martins, 1974). O problema da tecnocracia representava naquele momento uma junção entre acumulação, ciência e prática tecnológica, formando um modo de produção em que o principal meio produtivo torna-se o conhecimento, e que este passa a ser detido por frações de classe hegemônicas que disputam espaço dentro da burocracia estatal.

A política não se realiza apenas por meio da ciência e tecnologia, mas enquanto prática científica e tecnológica. Marcado pela perspectiva weberiana de análise sobre o fenômeno burocrático, esse debate trazido por Habermas no final dos anos 1960 aproximou a questão tecnológica do processo de tomada de decisões.

Em sua análise sobre a tecnocracia moderna, Martins (1974) frisa que tecnocratas e tecnólogos são grupos que possuem importância diferenciada dentro da prática técnica, e que essa distinção precisa ser sublinhada. $\mathrm{O}$ erro de muitas correntes sociológicas que estudam a questão tecnológica foi subestimar essa clivagem e tratar os dois grupos indistintamente. 
Essa relação entre os técnicos e os não-técnicos, mas com decisão sobre a prática tecnológica, é complexa no mundo contemporâneo. $\mathrm{O}$ engenheiro e sociólogo Abraham Moles (1994) afirma que os engenheiros precisam trabalhar com cadernos de encargos, um roteiro de suas atividades que é prescrito por gestores e administradores. Com isso, eles precisam se dividir entre a modéstia e a autonomia, de modo a conservarem seu conhecimento e aceitarem as imposições do patrão ou príncipe.

Os cadernos de encargos são produzidos por um engenheiro solicitante (em outros termos, um gestor) e dirigidos a um engenheiro executante (técnico) a implementá-lo. Para o autor, essa divisão de tarefas não é problemática, pois garante a possibilidade relativa de autonomia aos dois agentes, solicitantes e executores.

A partir dos anos 1990 a discussão sobre inovação tecnológica foi fortemente marcada pela perspectiva da Sociedade do Conhecimento e pelas formas de difusão e interatividade da informação. A gestão da informação e da produção de conhecimento passou a ser um aspecto central desse debate, de forma que a problemática da inovação tornou-se menos um assunto tecnológico ou político e mais administrativo e gerencial (Gibbons et al., 1994).

A interação das firmas com e no sistema passa a adquirir significado estratégico e os padróes de eficiência dependem do domínio de práticas organizacionais complexas. Essas capacidades, que anteriormente eram consideradas como que mais puramente administrativas ou gerenciais, são consideradas no período atual como parâmetros de inovação (Lemos, 2000).

A produção e circulação de conhecimento, tácito ou codificado, passam a ser considerados um elemento essencial para a efetivação das práticas de inovação tecnológica.

"A capacidade de gerar, de adaptar/recontextualizar e de aplicar conhecimentos, de acordo com as necessidades de cada organização, país e localidade, $e ́$, portanto, central. Desse modo, tão importante quanto a capacidade de produzir novo conhecimento é a capacidade de processar e recriar conhecimento, por meio de processos de aprendizado; e, mais ainda, a capacidade de converter esse conhecimento em ação, ou, mais especificamente, em inovação...". (Albagli \& Maciel, 2004:10) 
A inovação depende menos de investimento intensivo de capital e inventividade técnica, e mais da criação de redes de circulação de informação e conhecimento. A problemática da inovação torna-se menos tecnológica e mais pedagógica, adquire um sentido econômico (distributivo) e social (coesão) que transcende os ditames operacionais e funcionais dos objetos técnicos.

Os arranjos organizacionais e os formatos interativos entre agentes científicos e econômicos tomam o centro do debate inovativo. O conteúdo específico de uma determinada tecnologia não é tão relevante quanto o arcabouço gerencial e o sistema cooperativo criado em seu entorno. Segundo Lemos,

"indica-se uma tendência crescente de constituição de formatos organizacionais específicos entre diferentes tipos de agentes sociais e econômicos, em ambientes propicios para a geração de inovaçôes, envolvendo desde etapas de pesquisa e desenvolvimento e produção, até a comercialização. Tais formas de interação vêm interligando as diversas unidades de uma empresa, bem como articulam diferentes empresas e outros agentes... visando promover uma fertilização cruzada de idéias, responder e se adequar às rápidas alteraçōes, com a promoção de mudanças e aperfeiçoamentos nas estruturas de pesquisa, produção e comercialização." (Lemos, 2000:170)

Todos esses aspectos apontam para um papel cada vez mais saliente de gerentes e policy-makers no arranjo de práticas tecnológicas mediante novos formatos organizacionais e interações, em que a forma se sobressai aos conteúdos das atividades tecnológicas concretas (Dosi, 1988; Freeman, 1992).

Para Stiegler (1998), esse excesso de planejamento e controle sobre o avanço tecnológico implica inserir constantemente variáveis não-técnicas que se sobrepõem à transformação propriamente técnica. Nos termos de Stiegler,

"em um ritmo de inovação constante, fatores desconhecidos não são mais aceitáveis; o movimento deve ser controlado sob o risco de haver um colapso na coerência global a partir de onde os sistemas operam de forma complementar...". (Stiegler, 1998:42)

Com isso, a capacidade de correr riscos ou realizar experimentações livres fica condicionada a certos aspectos e operações, não fazem mais parte 
das atividades cotidianas de uma empresa ou laboratório, uma vez que todo um aparato institucional, financeiro e econômico é construído em torno da inovação.

No limite, poder-se-ia pensar que o valor de uma inovação independe de seus aspectos intrínsecos, mas relaciona-se à capacidade gerencial que se investe em determinado objeto. Em outras palavras, qualquer tecnologia pode ser válida, desde que bem gerenciada.

Aponta-se uma crise do gesto técnico enquanto intermediário entre homens e o meio social, no qual tende a reduzir a inovação a certas prática formais. De uma atividade humana aberta e flexível, a inovação tecnológica precisa se adequar sistemicamente a uma agenda social antecipatória e imperativa, que submete os agentes tecnológicos a cronogramas e metas determinadas (Stiegler, 1998). Como abordar essa problemática da autonomia dos técnicos e da experimentação dentro dos parâmetros modernos da inovação tecnológica? Na próxima seção será mostrado como autores de diferentes áreas têm lidado com esse tema.

\section{A experimentação técnica e a inovação}

Como foi visto, diferentes autores e tendências apontam os problemas e desafios da experimentação e da gestão dentro das atividades de inovação tecnológica. O gesto técnico precisa cada vez mais se adaptar aos não-técnicos Há uma tendência crescente de firmas e outras instituiçôes estabalecerem padrões de gestão mais aprimorados que guiem e antecipem as atividades dos técnicos e engenheiros, o que provoca tensões diferenciadas em termos de expectativas tecnológicas e práticas administrativas.

A questão da experimentação técnica é um tema especialmente importante na filosofia e sociologia das técnicas (Callon et al., 2001). Diversos autores têm discutido a importância da autonomia e atuação dos técnicos para o avanço e coerência dos sistemas tecnológicos, o que possui diversas implicações para se compreender a lógica da inovação.

Correntes da Filosofia das Técnicas apontam que a construção de uma agenda de inovação sofre sérios abalos à medida que os agentes técnicos precisam submeter sua inventividade e aptidôes a imperativos de outras áreas. 
A Filosofia das Técnicas adentrou fortemente nesse debate nos anos 1950, tendo ainda grandes repercussões no pensamento contemporâneo. A teoria da concretização formulada pelo filósofo Gilbert Simondon (1969) contribui fortemente para essa discussão. Em seus estágios iniciais, os objetos são considerados abstratos ou artificiais por não possuírem uma coesão interna e os homens precisarem constantemente intervir para garantir seu funcionamento. Um exemplo dessa fase precária dos objetos técnicos corresponde a sua configuração como ferramentas ou utensílios, totalmente dependentes da manipulação humana. À medida que os objetos evoluem, a necessidade de participação humana diminui. Segundo o próprio Simondon,

"com a evolução, esse objeto perde seu caráter artificial: a artificialidade essencial de um objeto ocorre porque o homem precisa interferir para manter o objeto existindo, protegendo-o contra o mundo natural e dando a ele uma forma separada de existência". (Simondon, 1969:46-7)

O objeto técnico concreto resulta em um corpo plenamente ajustado, guardando várias semelhanças para com os seres vivos. Ele não precisa mais de um suporte exterior que possibilite seu rendimento. Ao contrário, ele pode existir tanto isoladamente quanto em associação com outros objetos, pois sua constituição integrada e sinérgica o faz prescindir de um suporte exterior.

Esta formulação adquire importância na medida em que fica aberta a possibilidade para uma conceituação diferente dos objetos técnicos, em que sua importância reside menos em uma funcionalidade restrita e mais no potencial criativo de compatibilidades internas. $\mathrm{O}$ motor de avióes é exemplo de objeto técnico mais concreto do que seu antecessor (o motor de carros), uma vez que não necessita de refrigeração por água, sendo este um recurso que implica regulação externa sobre o objeto. Segundo argumento do próprio Simondon,

“...em um motor de combustão interna, a refrigeração pode ser realizada por um subconjunto inteiramente autônomo; se esse subconjunto pára de funcionar, o motor se deteriora; se, ao contrário, a refrigeração é realizada por um efeito solidário do funcionamento do conjunto, o funcionamento implica refrigeração...". (Simondon, 1969:25) 
A necessidade de refrigeração por água representa a falta de articulação entre as engrenagens internas do motor e demanda a intervenção pontual de um elemento externo, o carburador, com uma função única e não-essencial. No objeto concreto, esse apêndice regulador desaparece e ele adquire uma feição mais sinérgica e recorrente.

Importante aqui salientar como Simondon concebe a eficácia técnica. $\mathrm{O}$ conceito de concretização altera os parâmetros de avaliação da esfera técnica, privilegiando mais diretamente a constituição compatibilizada e sinérgica dos objetos e seus dispositivos. Dessa forma, os objetos não são avaliados segundo uma perspectiva utilitária e antropocêntrica, mas de acordo com parâmetros mais propriamente técnicos.

O motor de aviōes apresenta uma articulação interna mais sofisticada, com um peso menor de acessórios não-essenciais e um ganho de coerência e auto-acoplamento. E de onde vem essa maior sinergia e auto-suficiência do motor dos aviōes, que tiveram um efeito posterior decisivo no desenvolvimento do automóvel?

Exatamente da experimentação contínua e do aperfeiçoamento pelo uso. Não foi o estabelecimento de metas exógenas à atividade tecnológica que permitiram um avanço nas formas de refrigeração dos motores e o posicionamento das asas, e nem a busca de rendimentos financeiros mais rápidos.

"Existe uma convergência de limitaçôes econômicas (diminuição de matéria-prima, de trabalho, e do consumo de energia durante a utilização) $e$ de exigências propriamente técnicas: o objeto [técnico] não deve ser autodestrutivo. Ele deve manter um funcionamento estável pelo maior espaço de tempo possivel. Desses dois tipos de causas, econômicas e propriamente técnicas, é necessário que as segundas predominem na evolução técnica...; sobretudo nos dominios em que as condiçôes técnicas prevalecem sobre as condições econômicas (aviação, material de guerra) ocorrem os progressos mais ativos...". (Simondon, 1969:26)

O investimento racionalizado em formulação de políticas e incentivos governamentais e financeiros à inovação tecnológica corre o risco de não atender a especificidades e propriedades que somente a atuação direta e contextualizada dos inovadores pode alcançar. É isso que o autor entende 
por predomínio das condições técnicas, o reconhecimento de que a articulação de objetos e sistemas tecnológicos atende a demandas específicas e não transferíveis.

Comparando a trajetória de desenvolvimento dos motores de aviōes e automóveis, Simondon afirma que

“...não é surpreendente que o scooter seja fruto do trabalho de um engenheiro especialista em aviação; enquanto o automóvel pode se permitir conservar residuos de abstração (refrigeração a água...), a aviação é obrigada a produzir objetos técnicos mais concretos, para aumentar a segurança e diminuir os pontos obscuros...". (Simondon, 1969:26)

$\mathrm{O}$ autor defende que o funcionamento dos objetos não se restringe a uma postura adaptativa ou defensiva frente a imposições sistêmicas, mas lança operadores, técnicos e objetos a um diálogo em aberto frente às possibilidades de articulação entre gesto humano, dispositivos e pensamento.

"O técnico só pode agir livremente, pois a normatividade técnica é intrinseca em relação ao gesto que a constitui; ela não é exterior ou anterior à ação... a normatividade técnica é intrinseca e absoluta...". (Simondon, 1989:263)

As normas da operação técnica são acessíveis aos indivíduos sem que ele precise se submeter a uma normatividade social. É a partir da operação técnica indutiva e experimental que os conjuntos técnicos ganham dinamismo e coerência, e avançam para configuraçôes mais ajustadas.

É importante constatar que mais recentemente a economia da inovação também vem corroborando essa perspectiva. Para Rosenberg (2006), um dos expoentes da teoria evolucionista das técnicas, a indústria de aviação representa um caso peculiar de desenvolvimento. Nela predomina um processo denominado de aprendizado pelo uso, um conceito essencial para se entender a inovação tecnológica em setores de alta complexidade. $\mathrm{O}$ aprendizado pelo uso se diferencia fortemente do aprendizado pela prática, na medida em que este último está intrinsecamente relacionada a estratégias econômicas e ao processo produtivo. 
O aperfeiçoamento tecnológico pelo uso pressupõe um acompanhamento dinâmico e complexo de um sem número de componentes e propriedades que ocorrem muito para além de sua significação econômica. Segundo Rosenberg,

“...numa economia com novas tecnologias complexas, existem aspectos essenciais da aprendizagem que são função, não da experiência envolvida na produção do produto, mas de sua utilização pelo usuário final... Assim, o aprendizado pelo uso refere-se a um local de aprendizagem muito diferente daquele da aprendizagem pela prática. Há muitas razóes por que isso deve ser assim. Talvez, em termos mais gerais, as características de desempenho de um bem de capital durável frequentemente não possam ser entendidas antes que se tenha tido uma prolongada experiência com ele." (Rosenberg, 2006:188-9)

Em outras palavras, em sistemas tecnológicos de grandes proporções, como no setor de aviação, não há como prever acuradamente a resistência dos materiais, o desempenho de componentes e a acoplação de engrenagens em novas cadeias de transmissão. O rendimento técnico tem que ser buscado continuamente dentro de uma margem de indeterminação cambiante.

$\mathrm{Na}$ indústria aeronáutica, o acompanhamento de projetos e o monitoramento do desempenho de novos modelos ocorre dentro de uma temporalidade estendida e por meio de uma confiança construída na interdependência entre os diferentes componentes de uma aeronave (fuselagem, asa, motor). A incerteza e a imprevisibilidade perfazem o cotidiano da tecnologia aeronáutica, e isso vem contrabalanceado por uma valorização da experimentação técnica.

Nesse ramo de atividade, o gerenciamento tecnológico a partir de matrizes de desempenho e ferramentas de prospecção não são fortemente úteis ao acompanhamento do aprendizado pelo uso, na medida em que tornam a especificidade dos objetos técnicos uma abstração.

Segundo Rosenberg, a tecnologia contemporânea solicita um tratamento cada vez mais específico e empírico, uma vez que

"boa parte do conhecimento técnico necessário nas sociedades de alta tecnologia tende a ser extremamente especializado ou especifico com respeito à natureza do processo e as máquinas envolvidas. Esse conhecimento não apenas não 
pode ser predito com precisão a partir dos princípios ou da metodologia da ciência, mas...ele tampouco pode sê-lo com base na experiência com tecnologias análogas ou correlatas". (Rosenberg, 2006:189)

Esse conhecimento também não pode ser gerenciado por uma ferramenta administrativa de avaliação de impactos, que submete diferentes inovaçôes a índices de desempenho e indicadores generalizados. Esses índices tendem a negligenciar a atuação específica de diferentes tecnologias e a criar um padrão médio e esperado de atuação, abstraindo as características e potenciais de uma dada máquina ou sistema tecnológico.

Rosenberg e Simondon, partindo de concepçôes tecnológicas distintas, convergem na identificação de problemas importantes relacionados à sistematização de práticas de inovação tecnológica. A experimentação livre e a exploração do funcionamento de objetos e sistemas técnicos permitem uma seleção de combinaçôes que, abertas ao acaso e acidentes, engendram novas possibilidades de funcionamento e operaçōes inusitadas. A inventividade técnica é, portanto, relativamente independente tanto da metodologia científica como da produção econômica.

A concepção antropomórfica que relaciona o desenvolvimento técnico com os interesses humanos e as metas sociais não consegue levar em conta a tendência a um aprimoramento do funcionamento sinérgico dos dispositivos técnicos. Eles se estabilizam a partir de um aumento da convergência de tendências na progressão de seu funcionamento. Para Stiegler,

"o que é próprio a um objeto técnico industrial é uma tendência a unificação de suas partes sob um todo que não é feito pelo homem que fabrica o objeto pensando em termos de funçôes, mas a partir de uma necessidade sinérgica a maior parte do tempo imprevista por ele...”. (Stiegler, 1994:252)

Ao responderem a ingerências impostas por metas corporativas, os técnicos criam um conflito velado entre, por um lado, as práticas de gestão tecnológica e as vicissitudes cotidianas da experimentação técnica de outro, como é patente na produção de aeronaves.

Para se entender o rumo das inovações técnicas, os setores mais avançados como aviação, informática e energia elétrica mostram que é necessário inves- 
tigar o sentido da prática dos engenheiros e seus materiais, o que inclui também elementos físicos e inanimados e um grau de indeterminação constitutivo da própria atividade técnica.

\section{Conclusão}

Os policy-makers e gestores industriais que organizam a inovação e estabelecem metas, projeções e mecanismos de avaliação buscam coordenar o avanço tecnológico no sentido de retirar seu aspecto de indeterminação e imprevisibilidade.

O estreitamento entre crescimento econômico e inovação tende a provocar uma descaracterização dos princípios tecnológicos à medida que a racionalização e modernização da esfera produtiva impõe padrões e projeções de resultados que não permitem uma abertura às múltiplas demandas coletivas e às aptidões tecnológicas de técnicos e pesquisadores.

Com isso, a prática tecnológica aparentemente se expande e ganha em coerência. Em realidade, a inovação precisa se submeter a projetos e cronogramas externos que conduzem a um fechamento de suas possibilidades, de modo que os resultados e indicadores são mais importantes que os processos e os experimentos. A formação de sistemas técnicos sofisticados depende tanto da coordenação de investimentos gerenciais e científicos como da inventividade dos criadores e programadores em seus estudos e experimentos.

A filosofia das técnicas das últimas décadas aponta que o grande surto inovativo do mundo contemporâneo pode ser acompanhado de uma perversão das possibilidades técnicas. $\mathrm{O}$ aumento no rendimento econômico da produção industrial pode resultar em uma profusão de equipamentos e acessórios não-essenciais, dotados de baixa sinergia e convergência, como no caso da indústria automobilística.

Ao enfatizar a gestão tecnológica em detrimento da experimentação técnica e da imponderabilidade dos arranjos sistêmicos das modernas tecnologias, a sociedade do conhecimento pode acumular informações e práticas que possibilitam controle sobre patentes e utensílios isolados, mas que não viabiliza encontros e compatibilidades do sistema técnico em sua complexidade e mutação. 
Por mais que o estabelecimento de fórmulas criativas de aprendizado institucional e qualificação gerencial possam estimular a produção e cruzamento de conhecimento, a busca de um aprofundamento e autonomia da experimentação técnica em sua abertura e contingência são elementos centrais para a construção de uma cultura técnica renovada

O pensamento social em diversas oportunidades apontou a crise do setor técnico no estabelecimento da lógica das práticas de inovação. Mesmo autores mais próximos da corrente schumpeteriano apontam os problemas advindos da crise da experimentação técnica na construção das aptidões tecnológicas, um tema que precisa ser continuamente aprofundado.

\section{Referências bibliográficas}

Albagli, S.; Maciel, M.L., "Informação e conhecimento na inovação e no desenvolvimento local”, Ciência da Informação, v.33, n.3, set.-dez., 2004.

Andrade, T., "Aspectos sociais e tecnológicos das atividades de inovação", Lua Nova, n.66, 2006.

Callon, M.; Lascoumes, P.; Barthe, Y., Agir dans um monde incertain, Paris: Seuil, 2001.

Cassiolato, J.E.; Lastres, H., "Sistemas de Inovação: políticas e perspectivas", Parcerias Estratégicas, n.8, p.237-255, 2000.

Castells, M., A sociedade em rede, São Paulo: Paz e Terra, 1999.

Dodgson, M., "As políticas para ciência, tecnologia e inovação nas economias asiáticas de industrialização recente", in Kim, L.; Nelson, R. (orgs.), Tecnologia, aprendizado e inovação, Campinas: Ed. Unicamp, 2005.

Dosi, G., Technical change and industrial transformation, Londres: McMillan, 1988.

Freeman, C., The economics of hope, Londres: Pinter, 1992.

, La teoria económica de la innovación industrial, Madri: Alianza Editorial, 1975. 
Gibbons, M. et al, The new production of knowledge, Londres: Sage, 1994.

Habermas, J., "Ciência e técnica como 'ideologia", São Paulo: Ed. Abril (col. Os Pensadores), 1983.

Lemos, C., "Inovação na era do conhecimento", Parcerias Estratégicas, n.8, p.157179, 2000.

Maciel, M.L., O milagre italiano: caos, crise e criatividade, Brasília: Paralelo 15, 1996.

, "Inovação e conhecimento", in Sobral, Fernanda et al. (orgs.), A alavanca de Arquimedes - ciência e tecnologia na virada do século, Brasília: Paralelo 15, 1997.

Martins, C.E., Tecnocracia e capitalismo, São Paulo: Ed. Brasiliense, 1974.

Moles, A., "Engenheiros e inventores hoje", in Scheps, R. (org.), O império das técnicas, Campinas: Ed. Papirus, 1994.

Rosenberg, N., Por dentro da caixa-preta, Campinas: Ed. Unicamp, 2006.

Schumpeter, J.A., Teoria do desenvolvimento econômico, São Paulo: Ed. Abril (col. Os Pensadores), 1982.

Simondon, G., Du mode d'existence des objets techniques, Paris: Aubier Montaigne, 1969.

, L'individuation psychique et collective, Paris: Aubier, 1989.

Stiegler, B., "La maieutique de l'objet comme organisation de l'inorganique", in Simondon - une pensée de l'individuation et de la technique, Paris: Albin Michel, 1994.

, Technics and time 1, Stanford: Stanford University Press, 1998.

Trigueiro, M.G.S., O clone de Prometeu, Brasília: Ed. UnB, 2002.

Zackiewicz, M., "Coordenação e organização da inovação: perspectives do estudo do futuro e da avaliação em ciência e tecnologia”, Parceiras Estratégicas, n.17, nov., 2003

ENDEREÇOS PARA CORRESPONDENCIA:

Thales Novaes de Andrade - thales@sigmanet.com.br

Rua Maria Adami Patarro, 495-7, Campinas, SP CEP 13084-280 